MATEC Web of Conferences 22, 05008 (2015)

DOI: $10.1051 /$ matecconf/ 20152205008

(C) Owned by the authors, published by EDP Sciences, 2015

\title{
Pinch Analysis on Regional Energy Allocation under Constraints of Carbon Emissions
}

\author{
Jiaping Zhu \& Zhiming Zhu \\ Department of Business, Hohai University, Nanjing, Jiangsu, China
}

\begin{abstract}
In view of high cost and constraints of carbon emissions in the development and utilization of new energy, the authors suggest to establish the energy allocation model of the fuels with minimal consumption and zero carbon emissions under constraints of total carbon emissions and their respective carbon emissions, in order to achieve a balanced energy supply and demand under carbon constraints. This paper proposes that Pinch analysis method shall be applied to the energy allocation under constraints of carbon emissions. The objective function and constraints of the model are synthesized and put in the same coordinate system to form the synthetic curve of energy demand and supply. The results of solution model of Pinch analysis method and the results of solution model of linear programming through analyzing the numerical examples to verify the feasibility and practicality of Pinch analysis method are compared.
\end{abstract}

Keywords: carbon constraints; Pinch analysis; energy allocation

\section{INTRODUCTION}

With the increasingly serious problems about global climate, the governments are asked to regard the protection of the environment as the prerequisite in developing their economies to achieve sustainable economic development and progress. Under the EU's promotion, the United Nations adopted the United Nations Framework Convention on Climate Change in 1992, which further became operable legal documents Kyoto Protocol in 1997. In these legal documents, the environmental problems are converted to climatic problems and then are technically converted to the problems of $\mathrm{CO} 2$ emissions. In order to become a leader in low-carbon revolution, low energy consumption, low pollution and low emission have been an inevitable trend of economic development of countries.

\section{RESEARCH STATUS}

At present, domestic and foreign scholars have carried out related researches on the questions of energy allocation. Starting from the concept of green supply chain, on the basis of the thoughts of environmental economics, Qingchen Shang established a set of evaluation indexes of green supply chain, and simply analyzed successful cases to verify its practicability; Shijun Zhang compared and analyzed the energy quota system in developed countries, then proposed the designed path of China's renewable energy quota system; FOO and others used the waterfall model to analyze the problems of energy program and energy allocation based on the constraint restricts of carbon emissions; Junying Zhang and others proposed to imple- ment carbon emission management to achieve the reduction of $\mathrm{CO}_{2}$ emissions, increase project earnings and lower project risks against the barriers of policies, technologies and funds existed in CCHP energy supply system on the construction of gas turbine in university campus; SCHROOTEN and others regarded Europe as the reference system to research maritime transport model based on vessel factors, transport factors and emission factors. LAM and others used P diagram to research the optimal synthetic model of supply chain, and constructed the system with the minimal carbon emissions; Qi Li and others used sectional data of China's energy consumption in 2005 to measure out energy consumption footprint in 30 provinces and autonomous regions. Jun Chen took regional differences of energy efficiency as the fundamental basis, by analyzing the issues on regional and optimal allocation of non-renewable energy to explore the internal laws and the realistic possibility on regional and optimal allocation of China's non-renewable energy sources; Xiaohong Chen and others regarded the European carbon credit trading system as an object to study the formation mechanism of the trading price, analyzed the trends and causes of EUA prices of two stages and established a EGARCH and EUETS model of carbon credit trading prices; Yingqing Zhang and others regarded government departments who formulate tax policies and the enterprises who cause environmental pollution in logistics activities as both sides of the two-player game, established and adopted the game model of price strategy under the conditions of imperfect information to obtain the tax rates of influencing equilibrium and the price levels of corporate products.

The documents mentioned earlier mainly consider either of these two objectives: the supply chain net- 
work with the minimal carbon emissions and the optimal allocation of the energy. But they did not study the combination of the two. This paper takes the regions as the research object, studies the object models under different constraints of carbon emissions and establishes an energy supply network with broader regions. This paper selects coal, oil, natural gas and zero carbon emission fuel in 10 regions as the research object, takes one of the regions as the origin to establish the coordinate system and uses Pinch analysis method to study regional energy allocation. The slopes of SCC energy and DCC energy separately represent the releasing factor and the bearing factor of different fuels on carbon emissions, in order to achieve the minimal use of zero carbon emission fuel under constraints of carbon emissions.

\section{REGIONAL ENERGY ALLOCATION MODEL UNDER CONSTRAINTS OF CARBON EMIS- SIONS}

\subsection{Model assumptions}

(1) If the total energy supply of coal, oil, and natural gas is more than the demand, it belongs to collection I; if the total energy supply is less than the demand, it belongs to collection $\mathrm{J}$.

(2) The zero carbon emission fuel in each region only supplies this region itself, and the supplied zero carbon emission fuel is unlimited.

(3) Each region pursues the minimum carbon emissions as the target, and the energy is transferred between the regions.

(4) The order of utilizing energy in each region with supply less than demand is natural gas, oil and coal.

\subsection{Model parameters}

$E_{z, j}$ represents the energy of zero-carbon emission fuel required in region $\mathrm{j}, \mathrm{TJ} ; B_{i, j, k}$ represents the total quantity of shipping fuel $\mathrm{k}$ from region i to region $\mathrm{j}$, t; $E_{k}$ represents the total quantity of fuel k provided for all regions, $\mathrm{t} ; V_{k}$ represents the combustion value of fuel $\mathrm{k}, \mathrm{TJ} / \mathrm{t} ; S_{j, k}$ represents the total quantity of fuel $\mathrm{k}$ provided for region $\mathrm{j}$ itself, $\mathrm{t} ; \mathrm{Dj}$ represents the total energy required for region $\mathrm{j}, \mathrm{TJ} ; \mathrm{e}_{o, k}$ represents the releasing factor on carbon emissions during the combustion of fuel $\mathrm{k}, \mathrm{t} / \mathrm{TJ} ; e_{i, j}$ represents the bearing factor on carbon emissions in region $\mathrm{j}, \mathrm{t} / \mathrm{TJ}$; Lj represents the limit level of carbon emissions in region $\mathrm{j}$ after adjustment.

\subsection{Model establishing}

It needs higher technical requirements and development costs to provide energy by using clean energy. So only from an environmental perspective, it is unrealistic. That means we also need to consider the cost factor. This paper combines both factors of environment and cost to achieve the minimum use of zero carbon emission fuel under constraints of carbon emissions in all regions.

$$
\begin{aligned}
& \min \sum_{j} E_{Z, j} \\
& \text { s.t. } \sum_{j} \sum_{j} B_{i, j, k} \leq E_{k}, \forall \mathrm{k} \\
& \sum_{i} \sum_{k}^{3} B_{i, j, k} V_{k}+\sum_{k}^{3} S_{j, k} V_{k}+E_{z, j}=D_{j}, \forall \mathrm{j} \\
& \sum_{i} \sum_{k}^{3} B_{i, j, k} V_{k} e_{o, k} \leq L_{j}, \forall ? \\
& E_{z, j}, B_{i, j, k} \geq 0, \forall \mathrm{i}, \mathrm{j}, \mathrm{k} .
\end{aligned}
$$

\subsection{Pinch analysis}

The horizontal axis and vertical axis of the coordinate separately represent the accumulated carbon emissions and accumulated energy demands. The steps of Pinch analysis methods are as follows:

(1) The region $\mathrm{j}$ within the collection $\mathrm{J}$ is arranged in ascending order of $e_{o, k}$ and $e_{I, j}$;

(2) Calculate the carbon emission level $\mathrm{E}_{\mathrm{k}} \mathrm{e}_{o, k}$ of 3 kinds of fuels and the adjusted limit level $\mathrm{Lj}$ of carbon emissions in region $\mathrm{j}$ after using the fuels with carbon emissions;

(3) Take total energy demand $\mathrm{Dj}$ in region $\mathrm{j}$ as $\mathrm{x}$-axis and take $\mathrm{Lj}$ as $\mathrm{y}$-axis to draw the DCC curve. The slope at each point of the DCC curve is the bearing factor of carbon emissions $e_{I, j}$;

(4) Take Ek as $\mathrm{X}$-axis and take the carbon emission level $\mathrm{E}_{\mathrm{k}} \mathrm{e}_{o, k}$ of the 3 kinds of fuels as $\mathrm{y}$-axis to draw the SCC curve. The slope at each point of the SCC curve is the releasing factor of carbon emissions $\mathrm{e}_{o, k}$;

(5) Make the DDC and SCC curves synthesized in the same diagram;

(6) Horizontally move the SCC curve to the right to ensure that the SCC curve does not intersect with the DCC curve. When all points of the SCC curve are moved to the bottom right of the DCC curve, the intersection point of the SCC and DCC curve at this time is Pinch point;

(7) The distance from the initial point to the leftmost point of SCC shows that the use of zero carbon emission fuel is the least under constraint conditions.

\section{THE ANALYSIS OF NUMERICAL EXAMPLES}

Take the 10 regions for example. The data on energy supply and demand and the data on the limits of carbon emissions in their relative locations are shown in Table 1. According to the data of World Energy Organization, the carbon emission factors for coal, oil, and natural gas are respectively $105,75,55 \mathrm{t} / \mathrm{TJ}$, and 
their combustion values are respectively $20.91,41.82$, $41.03 \mathrm{GJ} / \mathrm{t}$. If they belongs to the collection I, we figure out their respective energy that can be used, the carbon emissions from the combustion of the total energy that each kind of fuel can be supplied within collection I; If they belong to the region J, we figure out their respective energy needs, their respective allowed amount of slack on carbon emissions (the carbon emissions after adjustment). The data on the energy supply and demand of each fuel is shown in Table 2.

According to the data in Table 2, the energy supply for four kinds of fuels is shown in Figure 1, DCC and SCC of the energy in three regions are shown in Figure 2. The bearing factors on carbon emissions are arranged in ascending order. The bearing factors in region $1,6,10$ are $20,50,100 \mathrm{t} / \mathrm{TJ}$ respectively. The overall bearing factor $\alpha$ on carbon emissions in three regions is the ratio of total carbon emissions or the limit of total carbon emissions and total energy demand, $\alpha=49 \mathrm{t} / \mathrm{TJ}$. Energy SCC of the three kinds of fuels is shown in Figure 1; Energy DCC in each region is shown as the solid line in Figure 2; if the three regions are taken as the whole, the energy DCC is shown as the dotted line in Figure 2. 
MATEC Web of Conferences

Table 1. The data of the analysis of numerical examples.
\begin{tabular}{|l|l|l|l|l|l|l|l|l|}
\hline Region & $\begin{array}{l}\text { Location/(km, } \\
\mathrm{km})\end{array}$ & Coal/Gt & Oil/Gt & $\begin{array}{l}\text { Natural } \\
\text { Gas/Gt }\end{array}$ & $\begin{array}{l}\text { Zero Car- } \\
\text { bon Emis- } \\
\text { sion Fuel/t }\end{array}$ & $\begin{array}{l}\text { Total Sup- } \\
\text { plied Energy } \\
\text { of 3 Fuels/ZJ }\end{array}$ & $\begin{array}{l}\text { Total De- } \\
\text { manded } \\
\text { Energy/Gt }\end{array}$ & $\begin{array}{l}\text { Regional Limit } \\
\text { of Carbon } \\
\text { Emission/Gt }\end{array}$ \\
\hline 1 & $(0,0)$ & 0.5 & 0.3 & 0.8 & $\infty$ & 0.06 & 2.86 & 60 \\
\hline 2 & $(4.1,0.2)$ & 24.0 & 30 & 16.0 & $\infty$ & 2.42 & 0.12 & 190 \\
\hline 3 & $(4.4,2.5)$ & 8.0 & 7.0 & 9.0 & $\infty$ & 0.83 & 0.41 & 60 \\
\hline 4 & $(5.3,2.4)$ & 4.5 & 9.0 & 13.0 & $\infty$ & 1.01 & 0.45 & 70 \\
\hline 5 & $(7.9,5.1)$ & 7.0 & 5.0 & 20.0 & $\infty$ & 1.18 & 0.32 & 80 \\
\hline 6 & $(6.4,5.5)$ & 5.0 & 8.0 & 8.0 & $\infty$ & 0.77 & 3.68 & \\
\hline 7 & $(2.4,6.8)$ & 9.0 & 12.0 & 15.0 & $\infty$ & 1.31 & 0.30 & 200 \\
\hline 8 & $(9.4,5.5)$ & 12.0 & 5.0 & 3.0 & $\infty$ & 0.59 & 0.45 & 100 \\
\hline 9 & $(3.2,6.6)$ & 3.0 & 8.0 & 12.0 & $\infty$ & 0.89 & 0.20 & 50 \\
\hline 10 & $(2.3,7.3)$ & 13.0 & 10.0 & 16.0 & $\infty$ & 1.35 & 2.89 & 60 \\
\hline
\end{tabular}

Table 2. Energy supply and demand of each fuel.

\begin{tabular}{|c|c|c|c|c|c|c|c|}
\hline $\begin{array}{l}\text { Fuel } \\
\text { Category }\end{array}$ & $\begin{array}{l}\text { Sup- } \\
\text { plied } \\
\text { Energy } \\
\mathrm{E}_{\mathrm{k}} / \mathrm{ZJ},\end{array}$ & $\begin{array}{l}\text { Carbon Emis- } \\
\text { sion Factor } \\
\mathrm{e}_{\mathrm{o}, \mathrm{k}} /(\mathrm{t} / \mathrm{TJ})\end{array}$ & $\begin{array}{l}\text { Carbon Emissions } \\
\text { of Fuels /Gt }\end{array}$ & $\begin{array}{l}\text { Region Need } \\
\text { Energy } \mathrm{j}\end{array}$ & $\begin{array}{l}\text { Demanded } \\
\text { Energy/ZJ }\end{array}$ & $\begin{array}{l}\text { Bearing Factor } \\
\text { of Carbon } \\
\text { Emissions } \mathrm{e}_{\mathrm{t}, \mathrm{j}} \\
/(\mathrm{t} / \mathrm{TJ})\end{array}$ & $\begin{array}{l}\text { Adjusted } \\
\text { Limit of } \\
\text { Carbon } \\
\text { Emissions } L_{j} \\
/ \mathrm{t}\end{array}$ \\
\hline Coal & 1.30 & 105 & 136.50 & Region 1 & 2.80 & 20 & 56.00 \\
\hline Oil & 2.94 & 75 & 220.50 & Region 6 & 2.91 & 50 & 145.50 \\
\hline $\begin{array}{l}\text { Zero } \\
\text { Carbon } \\
\text { Emission } \\
\text { Fuel }\end{array}$ & $\geq 1.28$ & 0 & & & & & \\
\hline Total & $\geq 7.25$ & & 452.15 & & 7.25 & & 355.50 \\
\hline
\end{tabular}

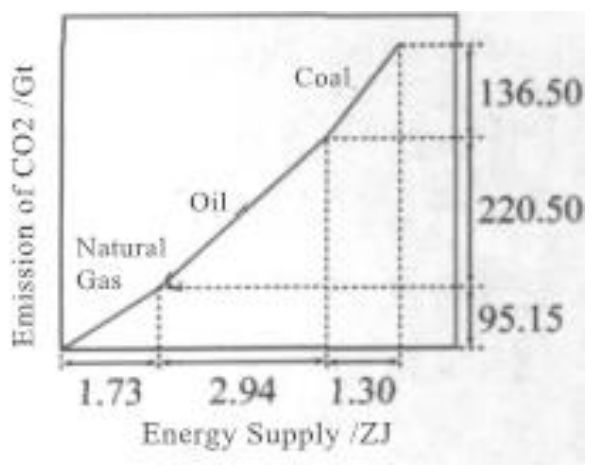

Figure 1. Energy Supply

4.1 Regional energy allocation model under Pinch analysis method

4.1.1 Energy allocation model under constraints of total carbon emissions

In view of the constraints of the total sum of the carbon emissions, energy DCC is shown as the dotted line in Figure 2. Determine the Pinch point according to the synthesized method of Pinch point, which is shown in Figure 3. The horizontal distance from the origin of coordinates to energy SCC is the energy

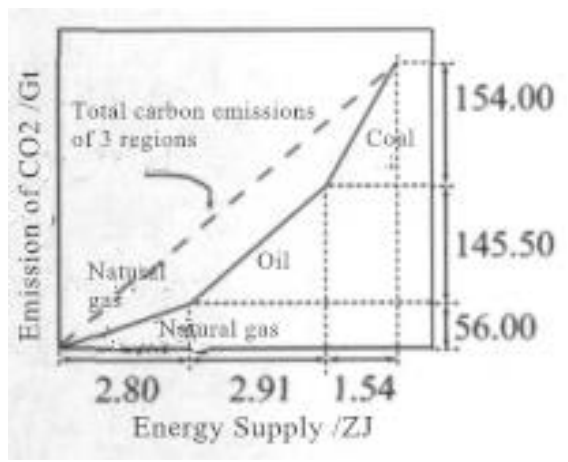

Figure 2. Energy Demand

provided by zero carbon emission fuel, $\Sigma_{\mathrm{j}} \mathrm{E}_{\mathrm{Zj}}=2.20 \mathrm{ZJ}$, the coordinate of the Pinch point $(7.25,355.50)$. In order to meet the constraint conditions of $\mathrm{CO} 2$, the energy of uncombusted coal is $0.92 \mathrm{ZJ}$. Taking into account the constraints of their own carbon emissions, the energy DCC is shown as the solid line in Figure 1; the Pinch point that have been found out by using energy SCC are shown in Figure 4. 


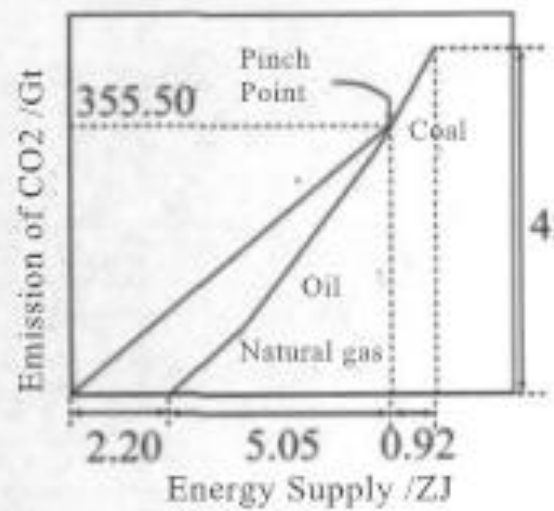

Figure 3. Energy supply and demand under constraints of total carbon emissions.

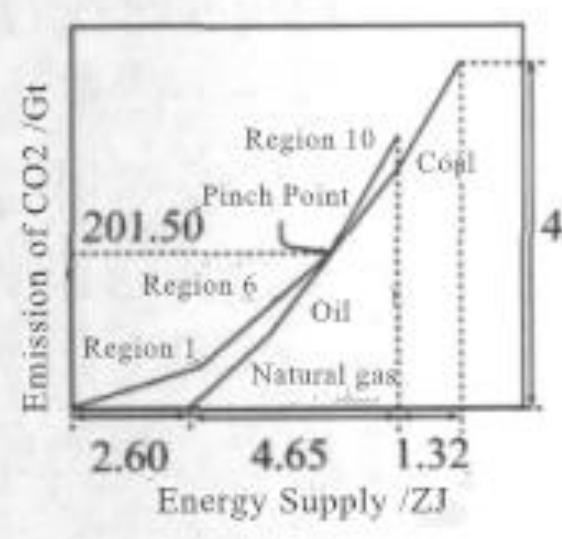

Figure 4. Energy supply and demand under their respective constraints of carbon emissions.

We can see the coordinate of the new Pinch point is $(5.71,201.50)$ from Figure 4. The energy of zero carbon emission fuel used is $2.60 \mathrm{ZJ}$. The bearing factor of carbon emissions $\mathrm{e}_{I, 10}=100 \mathrm{t} / \mathrm{TJ}$. The releasing factor of carbon emissions $e_{O, 10}=75 \mathrm{t} / \mathrm{TJ}$. The slope of energy SCC is lower than the slope of the energy DCC above the Pinch points. Therefore, $\mathrm{e}_{I, j}>e_{O, j}$, and the energy demand in the region can also meet the constraint conditions of carbon emissions in the system without the use of zero carbon emission fuel.

$$
\begin{aligned}
& x_{31}+x_{32}+x_{33}+x_{34}=1.54 \\
& 105 x_{11}+75 x_{12}+55 x_{13} \leq 56 \\
& 105 x_{21}+75 x_{22}+55 x_{23} \leq 145.5
\end{aligned}
$$

4.1.2 Energy allocation model under respective constraints of carbon emissions

Considering the realization of the least carbon emissions in the whole system under respective constraints of carbon emissions, the fuels in the ascending order of eo.j is used, that is, it is used in the order of natural gas, oil and coal to meet the energy needs. It is allocated according to the above golden rules, and the results are shown in Figure 5.

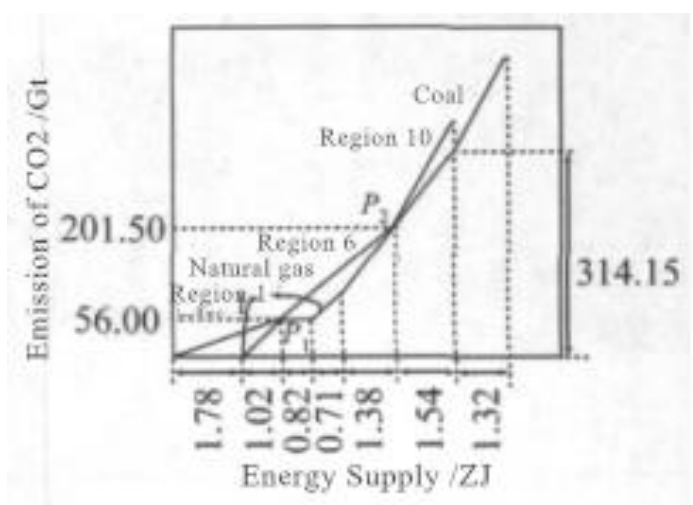

Figure 5. Energy supply and demand in each region under Pinch method.

Two Pinch points can be seen in Figure 5. P1 (2.80, $56.00)$ meets energy needs and carbon emission constraints in region 1. P2 $(5.71,201.50)$ meets energy needs and carbon emission constraints in region 6; the energy of zero carbon emission fuel used in region 1 is $1.78 \mathrm{ZJ}$.

\subsection{Linear programming model under the MATLAB}

Assuming that the energy of the fuel being allocated to each region is xij, the regions $1,6,10$ are respectively $i$ $=1,2,3$; coal, oil, natural gas and zero carbon emission fuel are respectively $\mathrm{j}=1,2,3,4$; then the energy allocation model is as follows:

$$
\operatorname{minf}(x)=x_{14}+x_{24}+x_{34}
$$

$$
\text { s.t. } x_{11}+x_{12}+x_{13}+x_{14}=2.80
$$

$x_{21}+x_{22}+x_{23}+x_{24}=2.91$

$$
105 x_{31}+75 x_{32}+55 x_{33} \leq 154
$$

$x_{11}+x_{21}+x_{31} \leq 1.3$

$x_{21}+x_{22}+x_{32} \leq 2.94$ 
MATEC Web of Conferences

$x_{13}+x_{23}+x_{33} \leq 1.73$

$x_{i j} \geq 0$

Use MATLAB to solve the above model. The results are shown in Table 4. The energy allocation is shown in Table 5. It follows from this that $\operatorname{minf}(\mathrm{x})=$ $2.562 \mathrm{ZJ}$.

Table 4. The energy needs solved by MATLAB in each region.

\begin{tabular}{|l|l|l|l|l|}
\hline $\begin{array}{l}\text { Region } \\
\text { Number }\end{array}$ & Coal & Oil & $\begin{array}{l}\text { Natural } \\
\text { Gas }\end{array}$ & $\begin{array}{l}\text { Zero Carbon } \\
\text { Emission } \\
\text { Fuel }\end{array}$ \\
\hline 1 & 0 & 0.4772 & 0.3674 & 1.9554 \\
\hline
\end{tabular}

\begin{tabular}{|l|l|l|l|l|}
\hline 6 & 0 & 0.9408 & 1.3626 & 0.6066 \\
\hline 10 & 0.4719 & 1.0681 & 0 & 0 \\
\hline
\end{tabular}

4.3 Comparison of results of Pinch analysis method and the MATLAB linear programming model

The comparative analysis result of Table 3 and Table 5 is shown in Table $6 . \mathrm{j}=2.6 \mathrm{ZJ}$, and the result solved by linear programming was $\Sigma \mathrm{jEZ}, \mathrm{j}=2.562 \mathrm{ZJ}$. $\Sigma \mathrm{jEZ}$ being obtained by these two methods, $j$ is very close to it. Because the retained decimal fraction is very different by these two methods, the error being produced by rounding can be ignored. It is considered that the object function being obtained by these two methods has the same result.

Table 3. The energy allocation of Pinch analysis method in each region.

\begin{tabular}{|c|c|c|c|c|c|c|}
\hline \multirow{2}{*}{$\begin{array}{l}\text { Region Number } \\
\& \text { Total Alloca- } \\
\text { tion }\end{array}$} & \multirow{2}{*}{ Demand } & \multicolumn{5}{|c|}{ Fuel Category } \\
\hline & & Coal & Oil & Natural Gas & Zero Carbon Emission Fuel & All Fuel \\
\hline \multirow{2}{*}{1} & Supplied Energy / ZJ & 0 & 0 & 1.02 & 1.78 & 2.80 \\
\hline & Carbon Emission / Mt & 0 & 0 & 56.10 & 0 & 56.10 \\
\hline \multirow{2}{*}{6} & Supplied Energy / ZJ & 0 & 1.38 & 0.71 & 0.82 & 2.91 \\
\hline & Carbon Emission / Mt & 0 & 103.50 & 39.05 & 0 & 142.55 \\
\hline \multirow{2}{*}{10} & Supplied Energy / ZJ & 0 & 1.54 & 0 & 0 & 1.54 \\
\hline & Carbon Emission / Mt & 0 & 115.50 & 0 & 0 & 115.50 \\
\hline \multirow{2}{*}{ Total Supplied } & Supplied Energy / ZJ & 0 & 2.92 & 1.73 & 2.60 & 7.25 \\
\hline & Carbon Emission / Mt & 0 & 219.00 & 95.15 & 0 & 314.15 \\
\hline
\end{tabular}

Table 5 . The energy allocation solved by MATLAB.

\begin{tabular}{|l|l|l|l|l|l|l|}
\hline \multirow{2}{*}{$\begin{array}{l}\text { Region Number \& } \\
\text { Total Allocation }\end{array}$} & \multirow{2}{*}{ Demand } & \multicolumn{2}{|c|}{ Fuel Category } \\
\cline { 3 - 8 } & & Coal & Oil & Natural Gas & Zero Carbon Emission Fuel & All Fuel \\
\hline \multirow{3}{*}{6} & Supplied Energy / ZJ & 0.00 & 0.48 & 0.37 & 1.96 & 2.80 \\
\cline { 2 - 8 } & Carbon Emission / Mt & 0.00 & 35.79 & 20.21 & 0 & 56.00 \\
\hline \multirow{3}{*}{10} & Supplied Energy / ZJ & 0.00 & 0.94 & 1.36 & 0.61 & 2.91 \\
\cline { 2 - 8 } & Carbon Emission / Mt & 0.00 & 70.56 & 74.94 & 0 & 145.50 \\
\hline \multirow{2}{*}{ Total Supplied } & Supplied Energy / ZJ & 0.47 & 1.07 & 0 & 0 & 1.54 \\
\cline { 2 - 8 } & Carbon Emission / Mt & 49.55 & 80.11 & 0 & 0 & 129.66 \\
\cline { 2 - 7 } & Supplied Energy / ZJ & 0.47 & 2.49 & 1.73 & 2.56 & 7.25 \\
\cline { 2 - 7 } & Carbon Emission / Mt & 49.55 & 186.46 & 95.15 & 0.00 & 331.16 \\
\hline
\end{tabular}


ICETA 2015

Table 6. The comparison of results of these two methods.

\begin{tabular}{|l|l|l|l|l|l|l|}
\hline \multirow{2}{*}{ Method } & \multirow{2}{*}{ Demand } & \multicolumn{7}{|c|}{ Fuel Category } \\
\cline { 3 - 8 } & & Coal & Oil & Natural Gas & Zero Carbon Emission Fuel & All Fuel \\
\hline \multirow{2}{*}{ Pinch Analysis } & Supplied Energy / ZJ & 0 & 2.92 & 1.73 & 2.60 & 7.25 \\
\cline { 2 - 7 } & Carbon Emission / Mt & 0 & 219.00 & 95.15 & 0 & 314.15 \\
\hline $\begin{array}{l}\text { MATLAB Linear } \\
\text { Programming }\end{array}$ & Supplied Energy / ZJ & 0.47 & 2.49 & 1.73 & 2.56 & 7.25 \\
\cline { 2 - 7 } & Carbon Emission / Mt & 49.55 & 186.46 & 95.15 & 0 & 331.16 \\
\hline
\end{tabular}

\section{CONCLUSIONS AND RECOMMENDATIONS}

Under today's environmental policy, the carbon emissions have become the essential environmental cost in supply chain. The research and analysis show that the use of zero carbon emission fuels is an effective way to solve the limit of the environmental pollution. But China is in its infancy stage of the development of clean energy sources. We should increase investment in technology development for the use of more zero carbon emission fuel in future. Under the carbon emission factors of different energy sources, set up synthetic curve of the energy of the whole regions, clearly show the object function of the minimum use of zero carbon emission fuel and regional carbon emission constraints with the chart, and solve the model by using MATLAB, in order to ensure that each region not only meets the demand and supply of the energy and its carbon emission constraints, but also makes the use of zero carbon emission fuel lower to the least under carbon emission constraints. However, Pinch analysis method has limitations in analyzing the problem of energy allocation, which can only analyze a kind of pollution emission in energy consumption. This paper mainly considers carbon emissions. Pinch analysis method can also be used in more complex mathematical model in energy management, especially which is very effective in the initial study of the energy plan. In the energy plan, this method can also be applied in other constraints, for example, carbon emission factors can be replaced by a specific cost. Then Pinch analysis method becomes the problem of the energy plan under the constraints of the cost. Then various constraint conditions can be considered in the model.

\section{REFERENCES}

[1] Shang, Q.C. 2009. The evaluation index of green supply chain based on environmental economics. Resource Science, 27(S1): 123-128.

[2] Zhang, S.J. 2007. Research on the Renewable Portfolio Standard. Journal of Natural Resources, 7(2): 19-23.

[3] FOODCY. TANRR. NGDKS. 2008. Carbon and footprint-constrained energy planning using cascade analysis technique. Energy, 33(10): 1480-1488.
[4] Zhang, J.Y., Wu, X.P., Shen, K. 2009. The analysis of clean development mechanism project of combined cooling-heating-power system. Journal of Shanghai Maritime University, 29(4): 60-64.

[5] SCHROOTENL, DEVLIEGERI. \& PANISLI, et al. 2009. Emissions of maritime transport: A European reference system. Sci. Total Environ., 408(2): 318-323.

[6] LAMHL. VARBANOVPS. KLEMEAJ. 2010. Optimisation of regional energy supply chain sutilising renewable P-graph approach. Computers \& Chem. Eng., 34(5): 782-792.

[7] Li, Q., Sun, G.N. \& H, Y.F. 2010. Regional variation and influencing factors of China's energy footprint. Statistics and Decision, (19): 111-113.

[8] Chen, J. 2010. Regional optimal allocation of China's non-renewable energy. Economic Management, 32(6): $1-8$.

[9] Chen, X.H. \& Wang, S.Y. 2010. Empirical research of European carbon emissions trading price mechanism. Scientific Progress and Policy, 27(19): 142-146.

[10]Zhang, Y.Q. \& Liu, J.J. 2010. Tax strategies of green logistics based on game model. Journal of Shanghai Maritime University, 31(1): 52-55. 